\title{
Does the BODE index reflect the level of physical activity in daily life in patients with COPD?
}

\section{O índice BODE reflete o nível de atividade física na vida diária de pacientes com DPOC?}

Leandro C. Mantoani', Nídia A. Hernandes',2, Mônica M. Guimarães', Renato L. Vitorasso', Vanessa S. Probst',3, Fábio Pitta',2

\begin{abstract}
Objectives: To study the relationship between the level of physical activity in daily life and disease severity assessed by the BODE index in patients with chronic obstructive pulmonary disease (COPD). Methods: Sixty-seven patients with COPD (36 men) with forced expiratory volume in the first second (FEV $)$ of $39(27-47) \%$ predicted and age of 66 (61-72) years old were evaluated by spirometry, dyspnea levels (measured by the Medical Research Council scale, MRC) and by the 6-minute walking test (6MWT). The BODE index was calculated based on the body mass index (weight/height ${ }^{2}$ ), FEV, MRC and 6MWT, and then the patients were divided in four quartiles according to their scores (Quartile I: 0 to 2 points, $n=15$; Quartile II: 3 to 4 points, $n=20$; Quartile III: 5 to 6 points, $n=23$; Quartile IV: 7 to 10 points, $n=9$ ). Two activity monitors (DynaPort ${ }^{\circledR}$ and SenseWear ${ }^{\circledR}$ ) were used to evaluate the level of physical activity in daily life. The Kruskal-Wallis test (Dunns's post-hoc test), the Mann-Whitney test and the Spearman Correlation Coefficient were used for statistical analysis. Results: There were modest correlation between the BODE index and the time spent walking per day, the total daily energy expenditure and the time spent in moderate and vigorous activities per day $(-0.32 \leq r \leq-0.47 ; p \leq 0.01$ for all variables). When comparing the pooled quartiles I+II with III+IV, there were significant difference between the time spent walking per day, the total daily energy expenditure and the time spent in moderate activities per day $(p \leq 0.05)$. Conclusion: The level of physical activity in daily life has a modest correlation with the classification of COPD severity assessed by the BODE index, reflecting only differences between patients with classified as mild-moderate and severe-very severe COPD.
\end{abstract}

Keywords: COPD; BODE index; physical activity in daily life.

\section{Resumo}

Objetivos: Estudar a relação entre nível de atividade física na vida diária (AFVD) e gravidade da Doença Pulmonar Obstrutiva Crônica (DPOC) avaliada pelo índice BODE. Métodos: Sessenta e sete pacientes com DPOC (36 homens), com volume expiratório forçado no primeiro segundo $\left(\mathrm{VEF}_{1}\right)$ 39(27-47)\%previsto, e 66(61-72)anos foram submetidos a avaliações de espirometria, grau de dispneia (Medical Research Council scale, MRC) e teste de caminhada de 6 minutos (TC6). O índice BODE foi calculado com base no índice de massa corpórea (peso/estatura²), VEF, $\mathrm{MRC}_{1}$ e TC6, e os pacientes foram subdivididos em quatro quartis de acordo com sua pontuação no BODE (quartil I: 0 a 2 pontos, $n=15$; quartil II: 3 a 4 pontos, $n=20$; quartil III: 5 a 6 pontos, $n=23$; quartil IV: 7 a 10 pontos, $n=9$ ). O nível de AFVD foi avaliado por dois monitores de atividade física (DynaPort e SenseWear ${ }^{\circledast}$ ). Os testes de KruskalWallis (pós-teste Dunns), Mann-Whitney e Coeficiente de Correlação de Spearman foram utilizados na análise estatística. Resultados: Houve correlação modesta entre os escores do índice BODE e o tempo gasto andando/dia, gasto energético total e tempo gasto/ dia em atividades moderadas e vigorosas $(-0,32 \leq r \leq-0,47 ; p \leq 0.01$ para todos). Quando comparados os quartis agrupados $I+I I$ com III+IV, houve diferença significante entre o tempo gasto andando/dia, gasto energético total e tempo gasto em atividades moderadas $(p \leq 0,05)$. Conclusão: O nível de AFVD apresenta correlação modesta com a classificação da gravidade da DPOC dada pelo índice BODE, refletindo apenas diferenças entre pacientes com doença leve-moderada e grave-muito grave.

Palavras-chave: DPOC; atividades de vida diária; BODE; TC6.

\section{Received: 02/04/2010 - Revised: 14/10/2010 - Accepted: 16/11/2010}

\footnotetext{
'Laboratory of Research in Pulmonary Physical Therapy, Physical Therapy Department, Universidade Estadual de Londrina (UEL), Londrina, PR, Brazi 2 Program of Master's degree in Physical Therapy, Physical Therapy Department, Universidade Estadual Paulista (UNESP), Presidente Prudente, SP, Brazil ${ }^{3}$ Universidade Norte do Paraná (UNOPAR), Londrina, PR, Brazil

Correspondence to: Fábio Pitta, Departamento de Fisioterapia, Universidade Estadual de Londrina, Hospital Universitário Regional Norte do Paraná, Rua Robert Koch, 60, Vila Operária, CEP 86038-440, Londrina, PR, Brasil, e-mail: fabiopitta@uol.com.br
} 


\section{Introduction : :}

Chronic obstructive pulmonary disease (COPD) is characterized by chronic airflow limitation not fully reversible and subsequent dyspnea ${ }^{1}$. In addition, the skeletal muscle dysfunction, a systemic manifestation of this disease, leads to a limitation of exercise capacity resulting in a reduction in physical activity levels in daily life 2 .

Physical activity in daily life (PADL) is considered as the total of voluntary movement produced by skeletal muscles above resting levels, carried out during the day ${ }^{3}$. The interest in assessing the amount of PADL performed by patients with COPD is growing, given that the lack of physical activity is clearly related to a higher occurrence of exacerbations and mortality in this population ${ }^{4-6}$. The objective measure of the PADL level through activity monitors has gained importance in the scientific literature due to the fact that these instruments have become more widely accessible?

Since COPD is a systemic disease, it is clear the need to categorize the patients according to their global characteristics. The BODE index (Body Mass-Index, Airflow Obstruction, Dyspnea and Exercise Capacity) has this goal ${ }^{8}$. The BODE index is a multidimensional grading system primarily used as a predictor of mortality risk in patients with COPD. However, this index has been widely used by the scientific community to classify the severity of COPD ${ }^{9-11}$. The use of the BODE index to determine the risk of hospitalizations due to exacerbations ${ }^{12}$ and as well as its use to predict response to pulmonary rehabilitation programs ${ }^{13}$ are examples of the use of this index outside the context of predicting mortality.

Despite the increasing scientific evidence of the BODE index and the objective measurement of the lack of physical activity in COPD, there are few studies that have investigated the relationship between the clinical characteristics of this disease severity (measured by the BODE index) and PADL level. A recent study of Watz et al. ${ }^{14}$ showed that there is a gradual reduction in the PADL level in COPD patients from a BODE index score 1 . However, no studies have accurately reported how remarkable (or not) are the differences in the PADL level among different scores and quartiles of the BODE index. Therefore, the aim of this study was to evaluate the relationship between the PADL level and the disease severity assessed by the BODE index.

\section{Methods : : :}

Sixty-seven patients with COPD who undertook an initial assessment for admission to the Pulmonary Rehabilitation
Program at the University Hospital of Londrina, Universidade Estadual de Londrina (HU-UEL), Londrina, PR-Brazil were recruited for this study. The inclusion criteria were: 1) diagnosis of COPD based on the criteria of the Global Initiative for Chronic Obstructive Lung Disease (GOLD) ${ }^{1}$; 2) clinical stability (absence of exacerbations) over the past three months, and 3) absence of osteo-neuro-muscular comorbidities that could interfere with the PADL assessment. All participants were informed about the procedures involved in the study and consented to participate signing an informed consent form. The study was approved by the Ethics in Research Committee of the UEL ( ${ }^{\circ}$. 061/06).

Initially, the participants underwent to a pulmonary function evaluation (spirometry, to measure the forced expiratory volume in the first second - $\mathrm{FEV}_{1}$, and other variables), to the assessment of exercise capacity ( 6 minutes walk test, 6MWT) and assessment of subjective sensation of dyspnea (Medical Research Council scale, MRC). Data such as age, weight, height and the body mass index (BMI) were collected for each participant. The BODE index was calculated based upon the variables BMI, 6MWT, MRC scale and $\mathrm{FEV}_{1} \%$ predicted, as originally described by Celli et al. ${ }^{8}$. Subsequently, the participants were divided into four groups according to their BODE index score (see topic BODE Index below). In addition, the PADL level was assessed through the use of two activity monitors, the DynaPort ${ }^{\circledR}$ Activity Monitor (DAM) (McRoberts, Netherlands) and the SenseWear ${ }^{\circledR}$ Armband (BodyMedia, USA). The activity monitors were used over two consecutive days, during 12 hours per day being the mean of the two days used for analyses, as previously described ${ }^{2}$.

\section{Spirometry}

The spirometry evaluation was performed by the Pony ${ }^{\circledR}$ spirometer (Cosmed, Italy). The procedure was performed according to the American Thoracic Society Guidelines ${ }^{15}$ determination of $\mathrm{FEV}_{1}$, forced vital capacity (FVC), $\mathrm{FEV}_{1} / \mathrm{FVC}$ and maximal voluntary ventilation (MVV) after the use of the bronchodilator medication. The reference values used were those proposed by Pereira et al. ${ }^{16}$.

\section{The Six -Minute Walk Test (6MWT)}

Two tests with an interval of 30 minutes, according to international standards ${ }^{17}$ were performed. The participants were instructed to walk as far as they could during 6-minutes on a flat corridor of 30 meters long. The reference values used were those suggested by Troosters, Gosselink and Decramer ${ }^{18}$. 


\section{Medical Research Council scale (MRC)}

The subjective sensation of dyspnea in daily life was measured by the MRC scale, validated in Portuguese ${ }^{19}$. This scale consists of only five items, in which the patients choose the item that corresponds to the degree which dyspnea limits their daily life.

\section{BODE Index}

The BODE index was calculated for each participant based on the combination of four variables, with the following scores: a measure of body composition (BMI) from 0 to 1 point; a measure of the intensity of airflow obstruction ( $\mathrm{FEV}_{1} \%$ predicted post-bronchodilator): from 0 to 3 points; a measure of subjective sensation of dyspnea (MRC scale): from 0 to 3 points and a measure of exercise capacity (walked distance in the 6MWT): from 0 to 3 points. The final score of the BODE index ranges from 0 to 10 points, being the higher the index value, the worse the patient's condition. For the analysis, the participants were divided into four quartiles according to their BODE index score, following to the classification recommended by Celli et al. ${ }^{8}$ as it follows: quartile I: 0-2 points; quartile II: $3-4$ points, quartile III: 5-6 points; quartile IV: 7-10 points. For comparative purposes, a second subdivision was performed allocating jointly patients with the BODE index score between 0 to 4 points (group "quartiles I-II") as well as patients with a score between 5 and 10 points (group "quartiles III-IV").

\section{Objective monitoring of the PADL level}

\section{Multi-sensor SenseWear ${ }^{\circledR}$ Armband (BodyMedia, USA)}

The SenseWear ${ }^{\circledR}$ was recently validated in patients with COPD $^{20}$. The SenseWear ${ }^{\circledR}$ is a relatively small $(8.8 \times 5.6 \times$ $2.1 \mathrm{~cm}$ ) and lightweight $(82 \mathrm{~g})$ device used in the superior and posterior area of the right arm (in the brachial triceps area). Information from a biaxial accelerometer added to other physiological sensors (i.e., responsible for analyzing the temperature variation and galvanic skin response) are used to estimate energy expenditure using the equations developed by the manufacturer ${ }^{21,22}$. These equations were based on the anthropometric characteristics such as gender, age, weight, height and dominant side of the participants. The main characteristic of this device is to provide the total energy expenditure in a certain period of time. In addition, the SenseWear ${ }^{\circledR}$ is able to classify the energy expenditure according to the intensity of activity. Therefore, for the present study, we used the energy expenditure in activities that require more than 3 METs, the time spent in sedentary activities per day ( $<3 \mathrm{METs}$ ), moderate (3 to $6 \mathrm{METs}$ ) and intense (between 6 and 9 METs) activities. The final report on each test was obtained through the analyses of the data collected by the device using a specific software (Innerview, BodyMedia, USA).

\section{DynaPort ${ }^{\circledR}$ Activity Monitor (McRoberts, Holland)}

The device consists of a small box positioned in the waist and an activity sensor attached to the lower limb of the individual by strips (total weight of 375 grams). This device has three motion sensors, being two of them located in the box attached to the waist and a third sensor attached to the lower limb, which aims to record acceleration, while the other two sensors aim to determine the body position. The DynaPort ${ }^{\circledR}$ is able to record the daily time spent in different activities and body positions, such as walking and standing, as well as the movement intensity $\left(\mathrm{m} / \mathrm{s}^{2}\right)$ measured during the time in which the individual is walking through the variation in the positioning of these sensors. The DynaPort ${ }^{\circledR}$ has been validated in patients with $\mathrm{COPD}^{23}$, and the minimum number of days needed to obtain a reliable assessment in this population (two days) was determined in a previous study ${ }^{2}$. After using the device, a specific software (DynaScope, McRoberts BV, Netherlands) was used to the read and analyze the data.

\section{Statistical analysis}

Statistical analysis was carried out using the GraphPad Prism ${ }^{\circledR} 3$ (GraphPad Software, San Diego, USA). The normality of data distribution was analyzed by the Kolmogorov-Smirnov test. The data were described as median (interquartile range). In general, the Kruskal-Wallis test with Dunn's post-test were used to compare the variables of the participants in different quartiles of the BODE index; the Mann-Whitney test was used to evaluate the differences in the PADL level between groups "quartiles I-II" and "quartiles III-IV" and the Spearman Correlation Coefficient was used to correlate the BODE index and PADL variables. Statistical significance was set at 0.05 for all analysis.

Taking into account the main correlation investigated in the study (total energy expenditure versus BODE index, which had the $\mathrm{r}$ value $=-0.47$ ) and using a two-tail test and alpha of 0.05 , the sample used in the present study $(n=67)$ has a power of 0.98 (98\%) for the proposed objective.

\section{Results : : :}

The characteristics of the 67 patients with COPD included in the study are shown in Table 1 . The participants 
were slightly overweight, have a moderate/severe airflow obstruction and have a reduction in functional exercise capacity, which was proportionally distributed according to gender. In the comparison of the quartiles of the BODE index, no difference was observed with regards to the anthropometric and demographic characteristics. As expected, a smaller number of participants were allocated in quartile $\mathrm{IV}$, and the significant differences observed between the quartiles $\left(\mathrm{FEV}_{1}\right.$, MRC, 6MWT) were justified by the severity of the disease.

Table 2 shows that, despite some statistically significant differences in the PADL level between quartiles I, II, III and IV, in general, the differences did not occur gradually between the quartiles, i.e., patients in the quartile II were not necessarily less active than those in the quartile I, and patients in the quartile IV were not necessarily less active than the those in the quartile III. Considering the total number of patients, the BODE index was modestly negative correlated with the time spent walking per day $(\mathrm{r}=-0.35$, $\mathrm{p}=0.004)$, the time spent standing per day $(\mathrm{r}=-0.32, \mathrm{p}=0.008)$ and the movement intensity $(\mathrm{r}=-0.39, \mathrm{p}=0.001$, Figure 1$)$. Other modest negative correlations observed were the total energy expenditure during the day (Figure 1), the energy expenditure above 3 METs and the time spent in moderate and vigorous activities $(-0.32 \leq \mathrm{r} \leq-0.47, \mathrm{p} \leq 0.009$ for all). In addition, the BODE index was modestly positive correlated with the time spent in sedentary activities during the day $(\mathrm{r}=0.41, \mathrm{p}=0.0001)$.

When compared to the patients in the quartiles III-IV, patients in quartiles I-II showed a higher time spent walking per day, time spent standing per day and movement intensity as well as higher energy expenditure in activities requiring more than 3 METs, spent more time in moderate and vigorous activities, spent more time in physical activities that require more than 3 METs and less time in sedentary activities per day (Figure 2) ( $\mathrm{p} \leq 0.05$ for all).

Table 1. Baseline characteristics of the patients included in the study.

\begin{tabular}{|c|c|c|c|c|c|}
\hline & Total & Quartile I (BODE 0-2) & Quartile II (BODE 3-4) & Quartile III (BODE 5-6) & Quartile IV (BODE 7-10) \\
\hline n (\% of total) & $67(100 \%)$ & $15(22 \%)$ & $20(30 \%)$ & $23(34 \%)$ & $9(13 \%)$ \\
\hline Gender (M/F) & $36 / 31$ & $6 / 9$ & $11 / 9$ & $15 / 8$ & $4 / 5$ \\
\hline Age (years) & 66 [61-72] & 62 [57-68] & 65 [61-73] & $67[61-74]$ & 67 [63-70] \\
\hline BMI (Kg/m2) & 26 [22-31] & 28 [24-31] & 26 [23-33] & 25 [22-27] & 22 [20-28] \\
\hline $\mathrm{FEV}_{1}(\mathrm{~L})$ & $0.93[0.69-1.28]$ & $1.34[1.24-1.73]$ & $1.12[0.80-1.41]$ & $0.83[0.67-0.94]^{\star *}$ & $0.60[0.52-0.82]^{\star \#}$ \\
\hline $\mathrm{FEV}_{1}(\%$ pred $)$ & $39[27-47]$ & 56 [44-63] & 43 [34-49] & $29[25-39]^{\text {*\# }}$ & $25[16-39]^{\star *}$ \\
\hline MRC (1 to 5) & $4.0[2.5-4.0]$ & $2.0[2.0-2.0]$ & $3.0[3.0-4.0]^{*}$ & $4.0[4.0-4.5]^{\star \#}$ & $5.0[4.0-5.0]^{* \#}$ \\
\hline 6MWT (m) & 424 [376-473] & 470 [427-529] & 437 [403-495] & $397[362-465]^{*}$ & $275[179-384]^{\star \#}$ \\
\hline 6MWT (\%pred) & 73 [63-82] & 82 [75-89] & 78 [69-84] & $68[60-74]^{* *}$ & $47[31-64]^{\star \#}$ \\
\hline GOLD (1 to 4) & $3.0[2.0-3.5]$ & $2.0[2.0-3.0]$ & $3.0[2.0-3.0]$ & $3.0[3.0-4.0]^{*}$ & $3.0[2.5-4.0]^{*}$ \\
\hline
\end{tabular}

$\mathrm{BMI}=$ body mass index; FEV $=$ forced expiratory volume in the first second; $\mathrm{MRC}=$ Medical Research Council scale; $6 \mathrm{MWT}=$ Six-minute walk test ; GOLD = Global Initiative for Chronic Obstructive Lung Disease. The values were described as median [interquartile range], except gender. For the between-groups comparison (quartile I to quartile IV) the Kruskal-Wallis test (Dunns' post hoc) was used. * $p \leq 0.05$ vs. Quartile I; ${ }^{*} p \leq 0.05$ vs. Quartile II.

Table 2. Comparison between physical activity in daily life in different quartiles of COPD severity classification according to the BODE index.

\begin{tabular}{|c|c|c|c|c|c|}
\hline & $\begin{array}{l}\text { General } \\
\text { Group }\end{array}$ & $\begin{array}{c}\text { Quartile I } \\
\text { (BODE 0-2) }\end{array}$ & $\begin{array}{l}\text { Quartile II } \\
\text { (BODE 3-4) }\end{array}$ & $\begin{array}{l}\text { Quartile III } \\
\text { (BODE 5-6) }\end{array}$ & $\begin{array}{l}\text { Quartile IV } \\
\text { (BODE 7-10) }\end{array}$ \\
\hline Walking Time (min/day) & 51 [34-73] & $52[41-96]$ & 59 [44-78] & $39[27-62]^{\star \#}$ & $16[12-68]^{\text {*\# }}$ \\
\hline Standing Time (min/day) & 237 [161-345] & 349 [252-385] & $254[173-293]^{*}$ & $185[135-318]^{*}$ & $183[80-372]^{\star}$ \\
\hline Moviment Intensity (m/s2) & $1.9[1.6-2.1]$ & $2.0[1.9-2.1]$ & $1.9[1.7-2.2]$ & $1.8[1.6-2.0]^{*}$ & $1.6[1.4-1.8]^{\star \#}$ \\
\hline TEE (Kcal/day) & 1091 [914-1389] & 1320 [1149-1542] & 1154 [992-1501] & $1019[806-1269]^{* \#}$ & $873[827-1015]^{\star *}$ \\
\hline $\mathrm{EE}>3 \mathrm{METS}$ & $135[51-381]$ & 366 [154-610] & 197 [113-408] & $74[9-159]^{\star \#}$ & $37[4-164]^{\star \#}$ \\
\hline Act. Time > 3 METS (min/day) & $29[10-86]$ & 75 [36-136] & 43 [24-107] & $19[3-42]^{\star *}$ & $9[2-41]^{\star \#}$ \\
\hline Time Spent in Sedentary activities (min/day) & 686 [627-710] & 645 [603-692] & 676 [610-691] & $699[684-718]^{\star \#}$ & $712[674-718]^{\star *}$ \\
\hline Time Spent in Moderate activities (min/day) & 31 [12-77] & 72 [36-111] & 44 [28-99] & $18[3-40]^{* *}$ & $9[2-40]^{\star \#}$ \\
\hline Time Spent in Vigorous activities (min/day) & $0[0-9]$ & $8[0-24]$ & $1[0-11]$ & $0[0-6]$ & $0[0-5]$ \\
\hline
\end{tabular}

TEE = total daily energy expenditure; EE > 3 METS = energy expenditure in activities demanding more than 3 metabolic equivalents (METs); Act Time = time spent per day in different intensities of physical activity, subdivided according to the type of activity performed (sedentary, moderate, vigorous), classified according to the respective METs. The values were described as medians [interquartile range]. Kruskal-Wallis test (Dunns post hoc test) was used. * $p \leq 0.05$ vs Quartile I; * $p \leq 0.05$ vs Quartile II. 

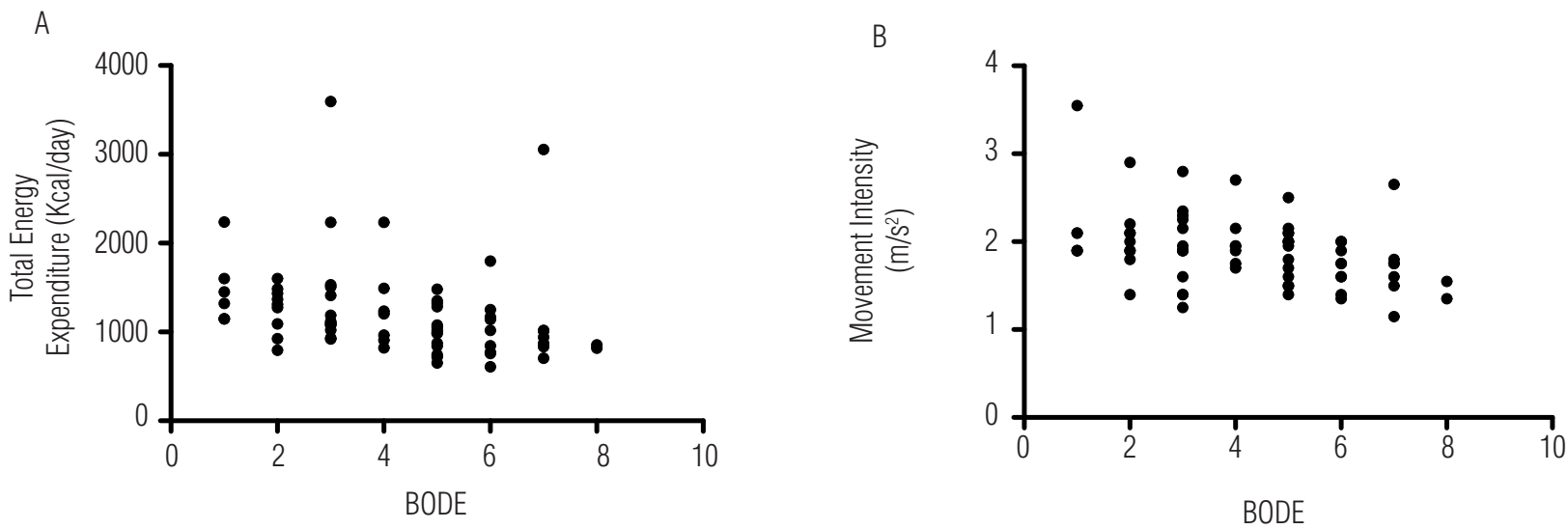

A: total daily energy expenditure, in Kcal $(r=-0.47 p<0.0001)$. B: Movement intensity during walking, in $\mathrm{m} / \mathrm{s}^{2}(\mathrm{r}=-0.39 ; \mathrm{p}=0.001)$ Spearman coefficient correlation was used for studying the relationships between variables of physical activity in daily life and the BODE index.

Figure 1. Relationship between BODE index and the two variables of physical activity in daily life in the group of patients included in the study ( $n=67$ ).

\section{Discussion $: \therefore$.}

The present study showed that the classification of COPD severity, according to the BODE index, has only modest correlation with the PADL level. It also showed that in patients with COPD, the BODE index mainly reflects the differences in the level of daily physical activity among patients with mild-moderate and severe-very severe disease. Such results can be attributed to the fact that, although patients with COPD classified by the BODE index in quartiles I and II have a reduced PADL level, this reduction is relatively similar in these quartiles, and more outstanding alterations in the PADL profile are reflected by the index in a more advanced stages of the disease (quartiles III and IV).

Previous studies have shown that the time spent walking and standing per day are reduced in patients with moderate to severe COPD compared to healthy elderly ${ }^{2,24}$. In agreement with these studies, the present results showed a very low PADL level in individuals with severe-very severe COPD (quartiles III and IV of the BODE index) when compared with those with mild-moderate COPD (quartiles I and II of the BODE index). Our findings showed that patients with scores equal or less than 4 in the BODE index have a higher daily time spent walking, increased total energy expenditure during the day, higher movement intensity during walking, higher time spent in physical activity > 3 METs, higher time spent in moderate activities and lower time spent in sedentary activities than individuals with scores above 5 , which reinforce the idea that people with more advanced COPD have lower PADL levels.

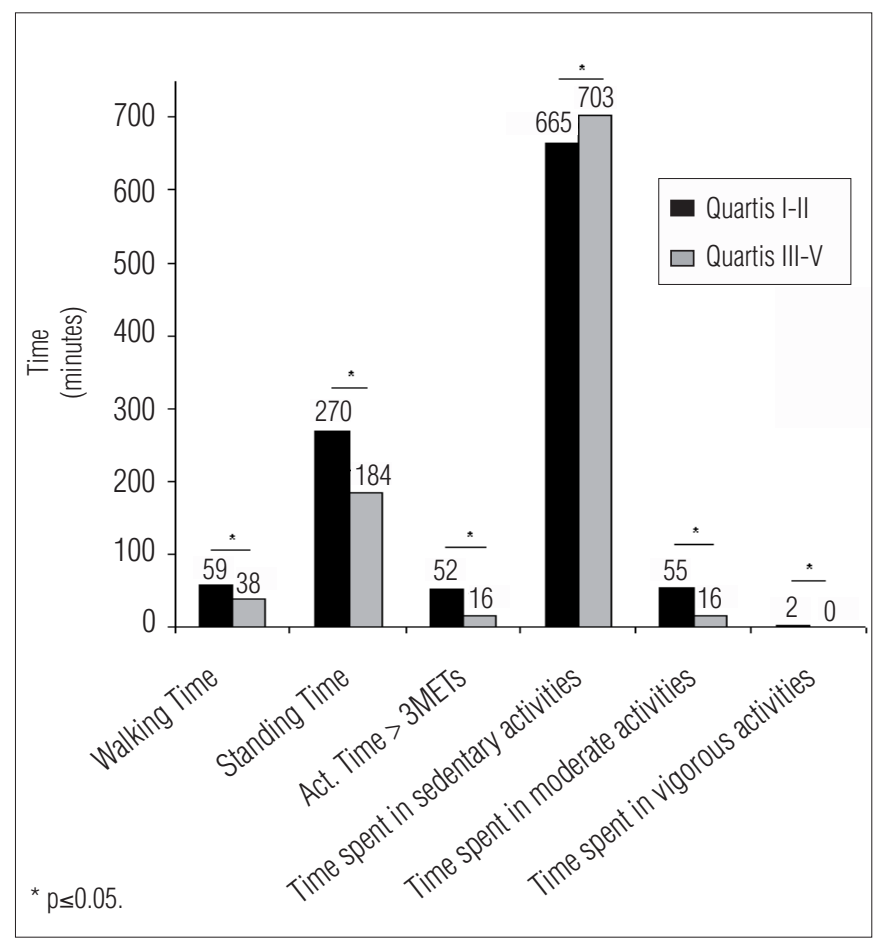

Figure 2. Comparison of time spent in different activities between groups divided into Quartiles I-II and Quartiles III-IV. Act. Time represents time spent per day in different intensities of physical activity, subdivided according to the type of activity performed (sedentary, moderate, vigorous), classified according to the respective METs. In order to compare groups the Mann-Whitney test was used.

In a study with patients with COPD, Watz et al. ${ }^{14}$ observed that there is a gradual reduction in the PADL level starting from the score 1 of the BODE index. However, this study did not precisely report the PADL level in different quartiles of the index as well as their relationship with the PADL level in 
this population. Another limitation that might be considered in the Watz et al. ${ }^{14}$ study, was that the authors used just an accelerometer as a tool for assessing PADL, which provides only variables related to energy expenditure and number of steps (SenseWear ${ }^{\circledR}$ Armband). Thus, it was not possible to quantify the time spent in different postures and movements during daily life. Equally or more important than the assessment of energy expenditure in physical activity is the quantification of the daily time spent on physical activity and the intensity with which it is performed. Therefore, by using not only the the DynaPort ${ }^{\circledR}$ but also the SenseWear ${ }^{\circledR}$, this study was able to demonstrate more thoroughly the various aspects concerning the PADL level in patients with COPD, as well as the PADL profile in patients with different levels of the disease severity, providing relevant additional information to the clinical practice.

Data from the current literature on the relationship between physical activity and clinical characteristics that reflect the severity of COPD are controversial or have not been deeply investigated. Such relationship has been demonstrated as varying from weak/moderate and not statistically significant to stronger and statistically significant. For example, the Pitta et al. ${ }^{2}$ study found weak correlations between daily time spent walking with $\mathrm{FEV}_{1}(\mathrm{r}=0.28)$ and BMI $(\mathrm{r}=-0.08)$, but strong correlation with the 6MWT $(r=0.76)$. In contrast, the Watz et al. ${ }^{14}$ study showed a moderate correlation between the level of physical activity and the variables $\mathrm{FEV}_{1}(\mathrm{r}=0.42)$, the distance covered during the 6MWT $(\mathrm{r}=0.46)$ and the degree of dyspnea measured by the MRC $(r=-0.44)$. On the other hand, in the study of Walker et al. ${ }^{25}$, the level of physical activity correlated better with $\mathrm{FEV}_{1}$ (most of variables with $\mathrm{r}$ values above 0.50 ) than with the 6MWT ( $\mathrm{r}$ values near to 0.30 ). The present results, therefore, showed a modest correlation between the variables of the PADL level and the clinical characteristics of the disease expressed by the BODE index $(-0.32 \leq \mathrm{r} \leq 0.41 ; \mathrm{p} \leq 0.001$ for all). Such differences observed between the present study and other studies with relatively conflicting results are possibly explained by differences in the characteristics of the used motion sensors to assess the PADL level, as well as differences in the characteristics of the populations involved in these studies (e.g., gender distribution, disease severity that characterized the sample and its ethnic and sociocultural profile).

The fact that possibly other factors that influence the PADL level in patients with COPD exist and that they are not measured by the BODE index, such as systemic inflammation and left heart dysfunction ${ }^{26}$, ventilatory reserve ${ }^{27}$ and levels of dynamic pulmonary hyperinflation ${ }^{28}$, may explain (at least partially) the modest relationship observed between the BODE index and the PADL level. In addition, particularities such as ethnic and sociocultural differences can influence the PADL level as showed by Pitta et al. ${ }^{29}$ and Garcia-Aymerich et al. ${ }^{30}$. These studies reinforce the hypothesis that the PADL level is influenced by many factors and that, even a multidimensional index for global evaluation of patients with COPD, as the BODE index, does not appropriate reflect how much each individual is physically (in)active in real life.

The limitations of this study include the fact that the sample belongs to only one research center, being conducted with patients who were interested in joining to a program of physical training, which limits the applicability and generalization of the results to different centers and clinical settings. However, compared with the current literature, the authors believe that this sample is representative of a population of patients with COPD in Brazil in terms of clinical and anthropometric characteristics. The number of days of the PADL monitoring (two consecutive days during the week, 12 hours a day) could also be considered as a limitation. However, Pitta et al. ${ }^{2}$ showed that this number of days is enough to obtain a valid estimate, using the DynaPort ${ }^{\circledR}$ Activity Monitor. To use the Multi-Sensor SenseWear ${ }^{\circledR}$ Armband, Watz et al. ${ }^{14}$ considered five days necessary to evaluate the PADL level, being two weekend days and three week days. In the present study, however, it was believed that, due to the fact of the sample was characteristically composed by sedentary individuals and to the fact that those individuals have been evaluated only in week days, that might have contributed to the decrease of the day by day variability and for a realistic estimate of the habitual level of physical activity in this population.

In summary, the classification of COPD severity given by the BODE index shows modest correlations with the PADL level, being able to reflect only differences in PADL level between patients with mild-moderate and severe-very severe disease.

\section{Acknowledgment $: \because$.}

To colleagues at the Research Laboratory of Pulmonary Physical Therapy for their support and assistance in data collection; to Antonio Fernando Brunetto, for the acquired knowledge, as well as to the UEL and the Conselho Nacional para Desenvolvimento Científico e Tecnológico ( $\mathrm{CNPq}$ - Brazil), for financial support. 


\section{References: ::}

1. Rabe KF, Hurd S, Anzueto A, Barnes PJ, Buist SA, Calverley P, et al. Global strategy for the diagnosis, management, and prevention of chronic obstructive pulmonary disease: GOLD executive summary. Am J Respir Crit Care Med. 2007;176(6):532-55

2. Pitta F, Troosters T, Spruit MA, Probst VS, Decramer M, Gosselink R. Characteristics of physical activities in daily life in chronic obstructive pulmonary disease. Am J Respir Crit Care Med. 2005;171(9):972-7.

3. Steele BG, Belza B, Cain K, Warms C, Coppersmith J, Howard J. Bodies in motion: monitoring daily activity and exercise with motion sensors in people with chronic pulmonary disease. $J$ Rehabil Res Dev. 2003;40(5 Suppl 2):45-58.

4. Garcia-Aymerich J, Lange P, Benet M, Schnohr P, Antó JM. Regular physical activity reduces hospital admission and mortality in chronic obstructive pulmonary disease: a population based cohort study. Am J Respir Crit Care Med. 2006;61(9):772-8.

5. Yohannes AM, Baldwin RC, Connolly M. Mortality predictors in disabling chronic obstructive pulmonary disease in old age. Age Ageing. 2002;31(2):137-40.

6. Pitta F, Troosters T, Probst VS, Spruit MA, Decramer M, Gosselink R. Physical activity and hospitalization for exacerbation of COPD. Chest. 2006;129(3):536-44.

7. Pitta F, Troosters T, Probst VS, Spruit MA, Decramer M, Gosselink R. Quantifying physical activity in daily life with questionnaires and motion sensors in COPD. Eur Respir J. 2006;27(5):1040-55.

8. Celli BR, Cote CG, Marin JM, Casanova C, Montes de Oca M, Mendez RA, et al. The bodymass index, airflow obstruction, dyspnea, and exercise capacity index in chronic obstructive pulmonary disease. N Engl J Med. 2004;350(10):1005-12.

9. Celli BR, Cote CG, Lareau SC, Meek PM. Predictors of Survival in COPD: more than just the FEV1. Respir Med. 2008;102 Suppl 1:S27-35.

10. Soler-Cataluña JJ, Martinez-Garcia MA, Sánchez LS, Tordera MP, Sánchez PR. Severe exacerbations and BODE index: two independent risk factors for death in male COPD patients. Respir Med. 2009;103(5):692-9.

11. de Torres JP, Pinto-Plata V, Casanova C, Mullerova H, Córdoba-Lanús E, Muros de Fuentes M, et al. C-reactive protein levels and survival in patients with moderate to very severe COPD. Chest. 2008;133(6):1336-43

12. Ong KC, Earnest A, Lu SJ. A multidimensional grading system (BODE index) as predictor of hospitalization for COPD. Chest. 2005;128(6):3810-6.

13. Cote CG, Celli BR. Pulmonary rehabilitation and the BODE index in COPD. Eur Respir J. 2005;26(4):630-6

14. Watz H, Waschki B, Meyer T, Magnussen H. Physical activity in patients with COPD. Eur Respir J. 2009;33(2):262-72

15. Miller MR, Hankinson J, Brusasco V, Burgos F, Casaburi R, Coates A, et al. Standardisation of spirometry. Eur Respir J. 2005;26(2):319-38.

16. Pereira CAC, Barreto SP, Simões JG, Pereira FWL, Gerstler JG, Nakatani J. Valores de referência para espirometria em uma amostra da população brasileira adulta. J Pneumol. 1992;18(1):10-22.
17. ATS Committee on Proficiency Standards for Clinical Pulmonary Function Laboratories. ATS statement: guidelines for the six-minute walk test. Am J Respir Crit Care Med. 2002;166(1):111-7.

18. Troosters T, Gosselink R, Decramer M. Six minute walking distance in healthy elderly subjects Eur Respir J. 1999;14(2):270-4

19. Kovelis D, Segretti NO, Probst VS, Lareau SC, Brunetto AF, Pitta F. Validation of the Modified Pulmonary Functional Status and Dyspnea Questionnaire and the Medical Research Counci scale for use in Brazilian patients with chronic obstructive pulmonary disease. J Bras Pneumol. 2008;34(12):1008-18

20. Patel SA, Benzo RP, Slivka WA, Sciurba FC. Activity monitoring and energy expenditure in COPD patients: a validation study. COPD. 2007:4(2):107-12.

21. Jakicic JM, Marcus M, Gallagher KI, Randall C, Thomas E, Goss FL, et al. Evaluation of the SenseWear Pro Armband to assess energy expenditure during exercise. Med Sci Sports Exerc 2004;36(5):897-904.

22. Fruin ML, Rankin JW. Validity of a multi-sensor armband in estimating rest and exercise energy expenditure. Med Sci Sports Exerc. 2004;36(6):1063-9.

23. Pitta F, Troosters T, Spruit MA, Decramer M, Gosselink R. Activity monitoring for assessment of physical activities in daily life in patients with chronic obstructive pulmonary disease. Arch Phys Med Rehabil. 2005;86(10):1979-85

24. Schönhofer B, Ardes P, Geibel M, Köhler D, Jones PW. Evaluation of a movement detecto to measure daily activity in patients with chronic lung disease. Eur Respir J. 1997 10(12):2814-9.

25. Walker PP, Burnett A, Flavahan PW, Calverley PM. Lower limb activity and its determinants in COPD. Thorax. 2008;63(8):683-9.

26. Watz H, Waschki B, Boehme C, Claussen M, Meyer T, Magnussen H. Extrapulmonary effects of chronic obstructive pulmonary disease on physical activity: a cross-sectional study. Am J Respir Crit Care Med. 2008;177(7):743-51.

27. Pitta F, Takaki MY, Oliveira NH, Sant'anna TJ, Fontana AD, Kovelis D, et al. Relationship between pulmonary function and physical activity in daily life in patients with COPD. Respir Med. 2008;102(8):1203-7.

28. Garcia-Rio F, Lores V, Mediano 0, Rojo B, Hernanz A, López-Collazo E, et al. Daily physica activity in patients with chronic obstructive pulmonary disease is mainly associated with dynamic hyperinflation. Am J Respir Crit Care Med. 2009;180(6):506-12.

29. Pitta F, Breyer MK, Hernandes NA, Teixeira D, Sant'anna TJ, Fontana AD, et al. Comparison of daily physical activity between COPD patients from Central Europe and South America. Respir Med. 2009;103(3):421-6.

30. Garcia-Aymerich J, Félez MA, Escarrabill J, Marrades RM, Morera J, Elosua R, et al. Physica activity and its determinants in severe chronic obstructive pulmonary disease. Med Sci Sports Exerc. 2004:36(10):1667-73 